EESTI NSV TEADUSTE AKADEEMIA TOIMETISED. XIV KOIDE

FOUSIKA-MATEMAATIKA- JA TEHNIKATEADUSTE SEERIA, 1965, NR. 2

ИЗВЕСТИЯ АКАДЕМИИ НАУК ЭСТОНСКОН ССР. ТОМ ХІV СЕРИЯ ФИЗИКО-МАТЕМАТИЧЕСКИХ И ТЕХНИЧЕСКИХ НАУК. 1965; № 2

\title{
КИНЕТИКА ОБРАЗОВАНИЯ КОМПЛЕКСНЫХ СОЕДИНЕНИИ ХЛОРИСТОГО ПРЕНИЛА С ЭЛЕКТРОФИЛЬНЫМИ ХЛОРИДАМИ МЕТАЛЛОВ
}

Катализаторы Фриделя-Крафтса-Густавсона, как координационно-ненасыщенные соединения, образуют комплексы донорно-акцепторного типа со многими неорганическими [1-3] и органическими [4,5] хлоридами. По литературным данным $\mathrm{SnCl}_{4}, \mathrm{TiCl}_{4}$ и другие хлориды металлов образуют с органическими кислородными соединениями (например, карбоновыми кислотами $\left[{ }^{6,7}\right]$ ) и их сложными эфирами [8] частично диссоциированные на ионы комплексы.

Известно, что наличие в алкильном радикале двойной связи в $\beta, \gamma$-положении облегчает диссоциацию $\mathrm{C}-\mathrm{Cl}$-связи на ионы под действием комплексообразующих катализаторов [9]. Однако из-за неустойчивости возникающих комплексных соединений химический характер и скорость образования их изучены весьма слабо.

Нами было установлено, что при взаимодействии хлористого пренила и электрофильных хлоридов металлов в инертных и достаточно полярных растворителях значительно увеличивается удельная электропроводность, высокочастотная проводимость и оптическая плотность раствора. Поскольку наблюдаемое резкое увеличение указанных параметров не может быть объяснено реакцией полимеризации (тем более, что опыты проводились с малыми концентрациями реагентов), то очевидно, что эти изменения обусловлены возникновением частично диссоциированных на ионы комплексных соединений. Например, по аналогии с процессом образования комплексного соединения с неорганическими хлоридами можно предполагать, что первичная реакция между хлористым пренилом и $\mathrm{SnCl}_{4}$ протекает следующим образом:

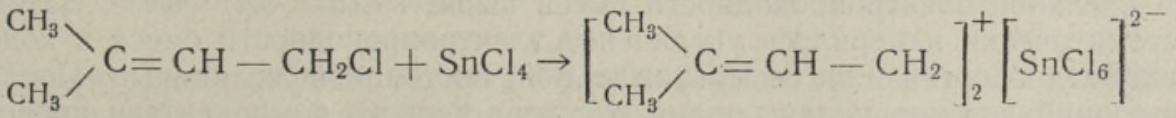

Для исследования оказалась особенно удобной реакция между хлористым пренилом и $\mathrm{SbCl}_{3}$, поскольку под действием $\mathrm{SbCl}_{3}$ полимеризация первого протекает очень медленно. В течение 20-30 часов (в присутствии $0,2-0,4 \% \quad \mathrm{SbCl}_{3}$ ) наблюдалось возникновение только $1-2 \%$ полимера. Поэтому влияние реакции полимеризации на электропроводность и на другие параметры среды можно не учитывать.

Так как химический состав возникающих комплексных соединений выяснен недостаточно, зависимость электропроводности и оптической плотности раствора от их концентрации неизвестна, поскольку указанные параметры зависят также от влияния степени диссоциации, ассоциации, сольватации молекул и ионов. Во избежание сольволиза реагентов ком- 
плексообразование проводили только в инертных растворителях, имеющих относительно низкую диэлектрическую проницаемость. В последних часто обнаруживаются отклонения от теоретических значений электропроводности, соответствующих уравнению Онзангера [10], - так называемые аномальные изотермы электропроводности.

В настоящей работе мы ставили своей целью доказать физическими методами возникновение комплексных соединений между хлористым пренилом и хлоридами металлов с незаполненной внешней электронной оболочкой·и выяснить основные закономерности этой реакции в различных условиях. Полученные результаты способствуют дальнейшему исследованию механизма и кинетики ионно-каталитической теломеризации изопрена с его гидрохлоридом $\left[{ }^{11,12}\right]$, поскольку комплексы указанного типа, по-видимому, являются в этой реакции активными промежуточными соединениями.

\section{Экспериментальная часть}

В качестве исходного вещества использовался продукт неполного гидрохлорирования изопрена [12]. Продукт освобождался от следов воды и спиртов нагреванием с борным ангидридом (при $40^{\circ} \mathrm{C}$ ) в атмосфере $\mathrm{CO}_{2}$.

Гидрохлорид изопрена разгонялся в вакууме при 100 мм рт. ст. на колонке эффективностью 16 теоретических тарелок. Для опытов использовалась фракция хлористого пренила $54-56^{\circ} \mathrm{C}$ (100 мм рт. ст.). По данным определения первичного хлора аллильного типа методом Лээтса [11] последняя содержала примесь изомера диметилвинилхлорметана (менее $10 \%$ ). $\mathrm{SnCl}_{4}$ и $\mathrm{TiCl}_{4}$ применялись в виде $10 \%$-ного раствора в дихлорэтане. Другие хлориды металлов вводили в раствор в твердом виде. Растворители тщательно сушили при помощи $\mathrm{CaCl}_{2}, \mathrm{Na}$ или $\mathrm{P}_{2} \mathrm{O}_{5}$, перегоняли и хранили в атмосфере сухого углекислого газа.

Определение удельной электропроводности среды при комплексообразовании проводилось при помощи реохордного моста Р-38; пределы измерения при частоте 50 гц составляли $10^{-6}-10^{-4}{o M^{-1}}_{c M^{-1}}$. Реакция проводилась в электролитической ячейке Х-38 (объем $50 \mathrm{M}$, константа $0,41\left(M^{-1}\right)$. Раствор был термостатирован при температуре 0 и $25^{\circ} \mathrm{C}$. Перед опытом измерялась электропроводность раствора исходных компонентов. Применялись только те растворы, удельная электропроводность которых была ниже $0,5 \cdot 10^{-6} \mathrm{OM}^{-1} \mathrm{CM}^{-1}$.

Опыты проводились путем медленного введения одного компонента в раствор другого компонента (при перемешивании) до повышения значения удельной электропроводности смеси выше $1 \cdot 10^{-6} O M^{-1} C M^{-1}$. Затем систематически измерялось увеличение электропроводности смеси в ходе реакции до достижения ее максимальной постоянной величины. После этого прибавлялась новая порция раствора первого компонента и проводили аналогичные измерения. Полученные результаты наносили на график в виде функции удельной электропроводности от продолжительности реакции или от концентрации прибавляемого компонента.

Измерения высокочастотной проводимости реакционной среды проводиліись при помощи датчика конденсаторного типа и прибора (частота $5 \mathrm{Mz \iota})$, работающего по методу биения двух генераторов. В качестве реактора применялся 130 мл стеклянный цилиндр, снабженный змеевиком для охлаждения, магнитной мешалкой и внешними электродами (емкость их в воздухе $8,9 n \phi)$. Увеличение оптической плотности среды во время процесса комплексообразования определяли проведением реакции непосредственно в кювете фотоэлектрического колориметра ФЭК-М. 
Параллельные кюветы заполняли раствором хлористого пренила и регулировали шкалу оптической плотности на нуль. В одну из кювет вводили хлорид металла в растворе или в твердом виде, перемешивали и определяли относительное изменение оптической плотности в ходе реакции.

Результаты некоторых опытов по измерению электропроводности среды после введения хлорида металла в раствор избытка хлористого пренила приведены в табл. 1. К растворителям предъявлялись следующие требования: 1) инертность к реагентам, 2) растворимость в них хлоридов металлов.

Таблица 1

Электропроводность среды при реакции хлоридов металла с хлористым пренилом (в избытке) при $25^{\circ} \mathrm{C}$

\begin{tabular}{|c|c|c|c|c|}
\hline \multicolumn{2}{|c|}{ Хлорид металла } & \multirow{2}{*}{ Растворитель } & \multirow{2}{*}{$\begin{array}{c}\text { Макси- } \\
\text { мальная } \\
\text { удельная } \\
\text { электро- } \\
\text { провод- } \\
\text { ность, } \\
\text {. } 10^{6} \\
\text { oм-1 }^{-1} \mathrm{cM}^{-1}\end{array}$} & \multirow{2}{*}{$\begin{array}{l}\text { Константа } \\
\text { скорости } \\
\kappa, \text { мин-1 }\end{array}$} \\
\hline $\begin{array}{l}\text { Фор- } \\
\text { мула }\end{array}$ & 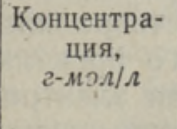 & & & \\
\hline $\mathrm{SnCl}_{4}$ & $\begin{array}{l}0,001 \\
0,039 \\
0,192\end{array}$ & $\begin{array}{l}\mathrm{CH}_{2} \mathrm{ClCH}_{2} \mathrm{Cl} \\
\mathrm{C}_{6} \mathrm{H}_{5} \mathrm{Cl} \\
\mathrm{CHCl}_{3}\end{array}$ & $\begin{array}{r}8,3 \\
20,3 \\
5,9\end{array}$ & $\begin{array}{l}0,020 \\
0,012 \\
0,017\end{array}$ \\
\hline $\mathrm{SbCl}_{3}$ & $\begin{array}{l}0,045 \\
0,036 \\
0,001\end{array}$ & $\begin{array}{l}\mathrm{CH}_{2} \mathrm{ClCH}_{2} \mathrm{Cl} \\
\left(\mathrm{CH}_{3} \mathrm{CO}\right)_{2} \mathrm{O} \\
\mathrm{C}_{6} \mathrm{H}_{5} \mathrm{NO}_{2}\end{array}$ & $\begin{array}{l}6,2 \\
5,3 \\
1,8\end{array}$ & $\begin{array}{r}0,037 \\
6,57 \\
41,40\end{array}$ \\
\hline $\mathrm{TiCl}_{4}$ & $\begin{array}{l}0,004 \\
0,126\end{array}$ & $\begin{array}{l}\mathrm{CH}_{2} \mathrm{ClCH}_{2} \mathrm{Cl} \\
\mathrm{CHCl}_{3}\end{array}$ & $\begin{array}{l}4,1 \\
6,1\end{array}$ & $\begin{array}{l}0,095 \\
0,012\end{array}$ \\
\hline $\mathrm{BiCl}_{3}$ & 0,032 & $\left(\mathrm{CH}_{3} \mathrm{CO}\right)_{2} \mathrm{O}$ & 5,8 & 0,150 \\
\hline $\mathrm{ZnCl}_{2}$ & $\begin{array}{l}0,018 \\
0,030\end{array}$ & $\begin{array}{l}\mathrm{CH}_{3} \mathrm{COCH}_{3} \\
\mathrm{CH}_{3} \mathrm{COOH} \text { (ледяная) }\end{array}$ & $\begin{array}{r}23,0 \\
5,1\end{array}$ & $\begin{array}{l}0,051 \\
0,214\end{array}$ \\
\hline $\mathrm{AlCl}_{3}$ & $\begin{array}{l}0,003 \\
0,018\end{array}$ & $\begin{array}{l}\mathrm{CHCl}_{3} \\
\mathrm{CH}_{3} \mathrm{COCH}_{3}\end{array}$ & $\begin{array}{r}20,0 \\
3,9\end{array}$ & $\begin{array}{l}0,139 \\
5,940\end{array}$ \\
\hline $\mathrm{HgCl}_{2}$ & 0,026 & $\mathrm{CH}_{3} \mathrm{COOH}$ (ледяная) & 4,0 & 0,032 \\
\hline $\mathrm{FeCl}_{3}$ & 0,0002 & $\mathrm{CH}_{2} \mathrm{ClCH}_{2} \mathrm{Cl}$ & 6,3 & Выше 50,0 \\
\hline
\end{tabular}

Концентрация хлорида металла была выбрана таким образом, чтобы максимальная удельная электропроводность осталась в пределах измерения прибора. В условиях большого избытка хлористого пренила кривые зависимости электропроводности от времени напоминают экспоненциальную кривую реакции первого порядка: $x=x_{\text {макс }}\left(1-e^{-k t}\right)$. (здесь

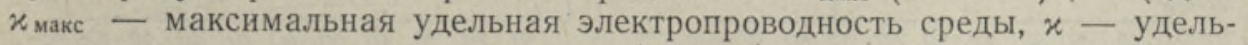
ная электропроводность среды через $t$ минут).

В узком интервале температур и концентраций реагентов удельную электропроводность можно считать пропорциональной содержанию комплексных соединений. Это дало возможность рассчитать константы скорости реакции комплексообразования, которые колеблются в широких пределах $\left(0,01-50,0\right.$ мин $\left.^{-1}\right)$ в зависимости от активности хлорида металла и характера растворителя. 
В случае некоторых активных хлоридов металлов $\left(\mathrm{FeCl}_{3}, \mathrm{AlCl}_{3}\right)$ и соответствующих растворителей реакция комплексообразования протекает сразу же по мере растворения хлорида металла в реакционной среде (доли секунды). Однако при уменьшении концентрации и активности

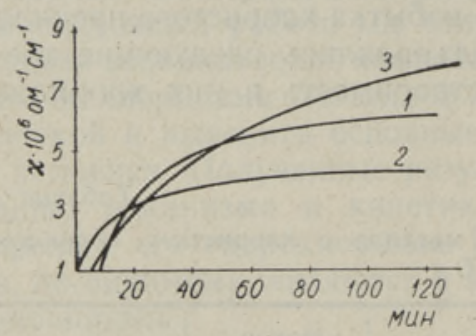
хлорида металла, а также диэлектричејской проницаемости растворителя скорость реакции, как правило, падала, что дало возможность исследовать ее кинетику с помощью физических методов.

Рис. 1. Кинетика образования комплекса хлористого пренила $(0,300 M)$ с $\mathrm{SnCl}_{4}, \mathrm{TiCl}_{4}$ и $\mathrm{SbCl}_{3}$ в дихлорэтане: $1-\mathrm{SbCl}_{3} 0,045 \mathrm{M} ; 2-\mathrm{TiCl}_{4}$ $0,004 M ; 3-\mathrm{SnCl}_{4} 0,001 M$.

Кинетику образования комплексных соединений характеризуют приведенные в виде графиков кривые увеличения электропроводности среды. На рис. 1 показано изменение электропроводности раствора после прибавления $\mathrm{SnCl}_{4}, \mathrm{TiCl}_{4}$ или $\mathrm{SbCl}_{3}$ к раствору хлористого пренила (в избытке) в дихлорэтане. Как видно из рисунка, удельная электропроводность в ходе реакции постепенно приближается к максимальному значению. Для достижения одинаковой максимальной удельной электропроводности, необходимо прибавлять к раствору хлористого пренила разные по весу количества хлоридов металлов. Ряд солей почти не растворяется в дихлорэтане (например, $\mathrm{BiCl}_{3}, \mathrm{ZrCl}_{4}, \mathrm{ZnCl}_{2}$ ), но после образования комплекса с хлористым пренилом переходят в раствор и увеличивают его электропроводность. Для повышения удельной электропроводности до $4-6 \cdot 10^{-6} o^{-1} c M^{-1}$ необходимо вводить в раствор с избытком хлористого пренила следующие количества хлоридов металлов (в 2-мол/л):

$$
\begin{array}{lll}
\mathrm{FeCl}_{3}-0,0002 & \mathrm{AlCl}_{3}-0,0013 & \mathrm{BiCl}_{3}-0,0032 \\
\mathrm{SnCl}_{4}-0,0004 & \mathrm{AlBr}_{3}-0,0015 & \mathrm{TiCl}_{4}-0,0040 \\
\mathrm{ZnCl}_{2}-0,0010 & \mathrm{ZrCl}_{4}-0,0017 & \mathrm{SbCl}_{3}-0,045
\end{array}
$$

Этот метод дает возможность выяснить и сопоставить каталитическую активность хлоридов металлов в ионнокаталитических реакциях превращения хлористого пренила и других производных аллилхлорида.

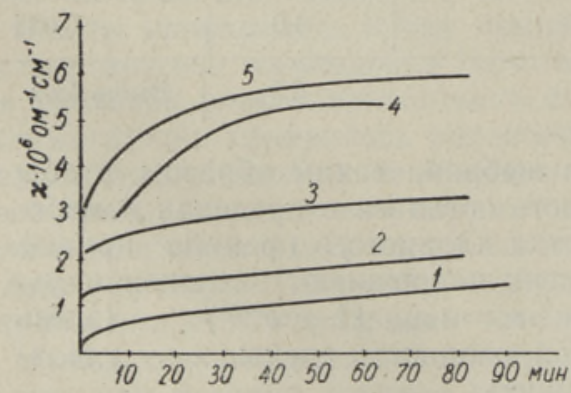

Рис. 2. Кинетические кривые образования комплексов в ледяной уксусной кислоте (хлористый пренил $0,05 M): 1-\mathrm{SbCl}_{3} 0,048 M ; 2-$. $\mathrm{HgCl}_{2} \quad 0,394 M ; 3-\mathrm{PrCl}_{3} \quad 0,067 M$; $4-\mathrm{ZnCl}_{2} \quad 0,030 M ; 5-\mathrm{BiCl}_{3} \quad 0,032 M$ (растворитель - уксусный ангидрид).

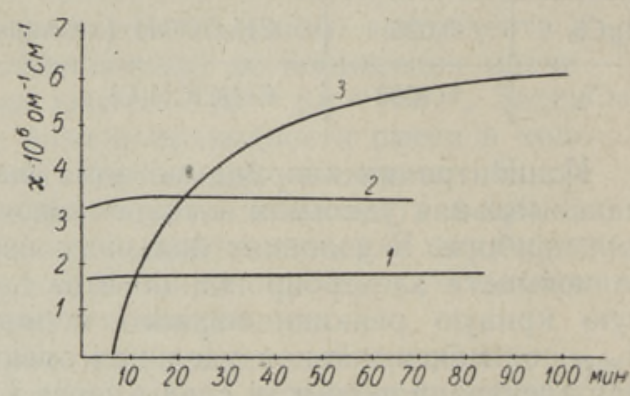

Рис. 3. Удельная электропроводность комплексов $\mathrm{SbCl}_{3}$ и хлористого пренила в неводных растворителях различной полярности (хлористый пренил 0,30M): 1 - нитробензол, $\mathrm{SbCl}_{3} 0,013 \mathrm{M} ; 2$ уксусный ангидрид, $\mathrm{SbCl}_{3} 0,036 \mathrm{M} ; 3-$ дихлорэтан, $\mathrm{SbCl}_{3} 0,045 \mathrm{M}$. 
В качестве растворителя для комплексообразования хлористого пренила с некоторыми хлоридами металлов можно применять и ледяную уксусную кислоту (рис. 2). Если сравнить количество вводимых в раствор хлоридов металла и соответствующие им электропроводности, то видно, что $\mathrm{HgCl}_{2}$ менее, а $\mathrm{ZnCl}_{2}$ более активен, чем $\mathrm{SbCl}_{3} . \mathrm{BiCl}_{3}$ и $\mathrm{SbCl}_{3}$ образуют комплексы с хлористым пренилом даже в таком полярном растворителе, как уксусный ангидрид (кривая 5). Диэлектрическая проницаемость растворителя оказывает заметное влияние на скорость образования комплексных соединений (рис. 3). В более полярных растворителях (уксусный ангидрид и нитробензол) комплекс $\mathrm{SbCl}_{3}$ с хлористым пренилом образуется почти моментально.

$\mathrm{C}$ целью выяснения порядка реакции между $\mathrm{SbCl}_{3}$ и хлористым пренилом нами было изучено влияние концентрации обоих компонентов на ее скорость. Как видно на рис. 4, увеличение исходной концентрации $\mathrm{SbCl}_{3}$ резко повышает как скорость реакции, так и максимальную удельную электропроводность (увеличение концентрации комплексов), однако константа скорости остается почти постоянной (около 0,01 $\mathrm{MuH}^{-1}$ ). Даже в условиях избытка хлористого пренила увеличение концентрации его повышает скорость образования комплекса (рис. 5). Это доказывает, что реакция имеет бимолекулярный характер и применение для расчета формул реакции первого порядка возможно только при большом избытке одного компонента.

Рис. 4. Зависимость скорости образования комплексных ионов от концентрации $\mathrm{SbCl}_{3}$ в условиях избытка $0,62 M$ хлористого пренила (при $\left.0^{\circ} \mathrm{C}\right)$ в дихлорэтане. $\mathrm{SbCl}_{3}: I-0,0094 M ; 2-0,0446 M$; $3-0,1000 M ; 4-0,2640 M$.

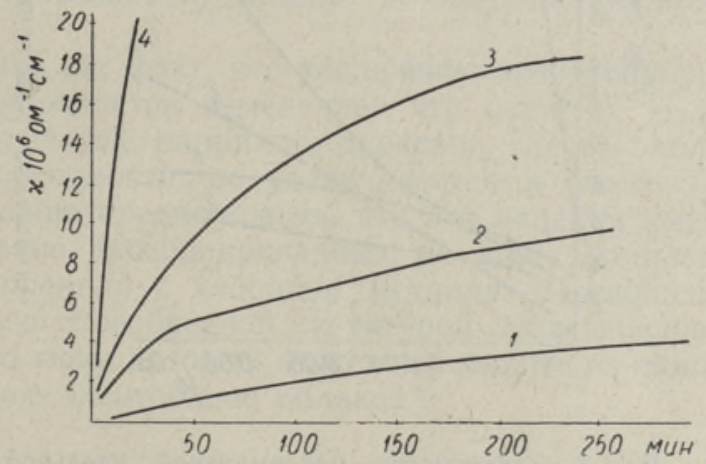

Қислородсодержащие растворители (такие, как сложные эфиры, кислоты, спирты и др.) могут быть применены в качестве среды для реакции образования указанных комплексных соединений только в том случае, если их комплексы с соответствующими хлоридами металлов менее прочны, чем комплексы с хлористым пренилом. Например, при растворении $\mathrm{ZnCl}_{2}$ и $\mathrm{AlCl}_{3}$ в ацетоне электропроводность растворов ниже

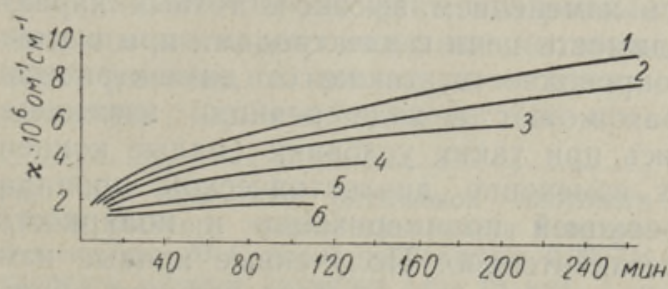

Рис. 5. Скорости образования комплекса хлорнстого пренила с $\mathrm{SbCl}_{3}(0,016 \mathrm{M})$ в дихлорэтане. Хлорнстый пренил: $1-3,080 \mathrm{M} ; 2-$ $1,552 M ; 3-0,934 M ; 4-0,614 M ; 5-0,174 \bar{M}$; $6-0,064 M$.

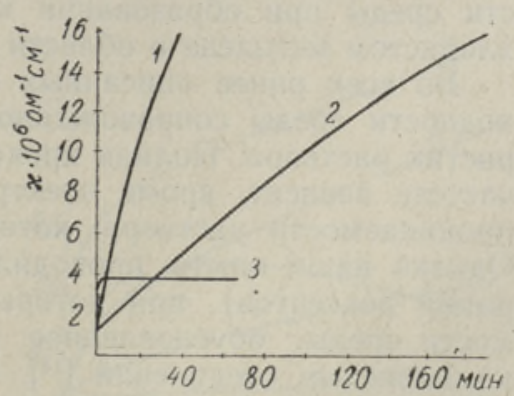

Рнс. 6. Скорость образования $0,018 M \mathrm{ZnCl}_{2}$ (1 н 2) или $\mathrm{AlCl}_{3}$ комплекса хлористого пренила с (3) в ацетоне (при $0^{\circ} \mathrm{C}$ ). Хлорнстый преннл: $1-0,280 M ; 2-$ $0,063 \mathrm{M} ; 3-0,280 \mathrm{M}$. 
$10^{-6}{ }_{\text {o }}{ }^{-1} c M^{-1}$, но повышается после прибавления хлористого пренила. Как видно из рис. 6, с повышением концентрации хлористого пренила скорость комплексообразования его с $\mathrm{ZnCl}_{2}$ увеличивается. Сравнение кривых 1 и 3 (рис. 6) показывает, что при одинаковой молярной концентрации компонентов в растворе комплекс $\mathrm{ZnCl}_{2}$ имеет бс́льшую максимальную удельную электропроводность, чем комплекс $\mathrm{AlCl}_{3}$. В ацетоне комплексы с хлористым пренилом образуют, кроме указанных хлоридов, также $\mathrm{FeCl}_{3}$ и $\mathrm{CuCl}$. Раствор $\mathrm{CuCl}$ в ацетоне сам имеет удельную электропроводность порядка $10^{-6} \mathrm{OM}^{-1} \mathrm{CM}^{-1}$. Однако при прибавлении к раствору хлористого пренила удельная электропроводность и оптическая плотность среды заметно повышаются.

На рис. 7 приведена зависимость максимальной удельной электропроводности растворов различных хлоридов металлов от молярной концентрации вводимого хлористого пренила (в области, близкой к эквивалентным концентрациям). Увеличение концентрации хлористого пренила ведет к почти пропорциональному повышению удельной электро-

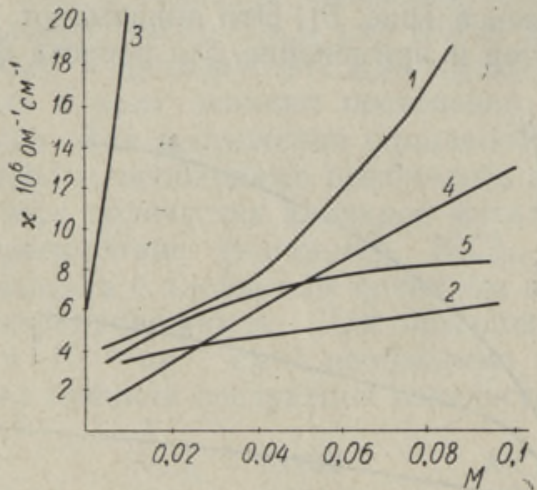

\begin{tabular}{|c|c|c|}
\hline 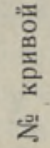 & Растворитель & $\begin{array}{c}\text { Хлорид } \\
\text { металла } \\
0,035 M\end{array}$ \\
\hline $\begin{array}{l}1 \\
2 \\
3 \\
4 \\
5\end{array}$ & $\begin{array}{l}\text { Уксусный ангидридд } \\
\text { То же } \\
\text { Дихлорэтан } \\
\text { Хлороформ } \\
\text { Ледяная уксусная } \\
\text { кислота }\end{array}$ & $\begin{array}{l}\mathrm{BiCl}_{3} \\
\mathrm{SbCl}_{3} \\
\mathrm{SnCl}_{4} \\
\mathrm{AlCl}_{3} \\
\mathrm{ZnCl}_{2}\end{array}$ \\
\hline
\end{tabular}

Рис. 7. Зависимость максимальной удельной электропроводности комплексов (в области, близкой к эквивалентным концентрациям реагентов) от концентрации хлористого пренила (см. таблицу).

проводности среды. В точке эквивалентных количеств хлорида металла и хлористого пренила резкого перелома кривой не наблюдается.

Нами исследовалось также изменение высокочастотной проводимости среды при образовании комплексных соединений в дихлорэтане и хлористом метилене в области различных частот от $10 \kappa 2 ц$ до 5 Мәц.

Во всех ранее описанных случаях увеличение удельной электропроводности среды сопровождалось изменением высокочастотных характеристик раствора. Полная проводимость цепи с электродами при высокой частоте зависит, кроме электропроводности, также от диэлектрической проницаемости раствора, которая может в ходе реакции изменяться. (днако наши опыты проводились при таких условиях (малые концентрации реагентов), при которых нзменение диэлектрической проницаемости среды, обусловленное реакцией полимеризации и полярностью комплексных соединений [14], незначительно. Полученные кривые изменения высокочастотной проводимости раствора в ходе реакции образования комплексных соединений по форме оказались похожими на соответствующие кривые изменения низкочастотной электропроводности. Например, при введении $\mathrm{SnCl}_{4}$ в раствор хлористого пренила в дихлорэтане кривые экспоненциально приближались к максимальному значению, причем последнее резко зависит от количества $\mathrm{SnCl}_{4}$. Эти резуль- 
таты дают возможность исследовать кинетику реакции образования указанных комплексов при помощи высокочастотных методов.

Для того, чтобы вызвать заданное изменение высокочастотной проводимости, необходимо вводить в раствор хлористого пренила различные количества хлорида металла, в зависимости от активности и химического характера последнего. На основании этого нами составлен аналогичный вышеописанному ряд активности хлоридов металлов. Например, для одинакового увеличения высокочастотной проводимости концентрированного раствора хлористого пренила в дихлорэтане необходимо вводить в раствор следующие количества хлорида (в \%):

$\begin{array}{lll}\mathrm{SnCl}_{4}-0,14 & \mathrm{AlBr}_{3}-0,23 & \mathrm{TiCl}_{4}-0,47 \\ \mathrm{ZnCl}_{2}-0,18 & \mathrm{ZrCl}_{4}-0,26 & \mathrm{SbCl}_{3}-4,00 \\ \mathrm{AlCl}_{3}-0,22 & \mathrm{BiCl}_{3}-0,36 & \end{array}$

Необходимо учесть, что изменение как низко-, так и высокочастотной проводимости при комплексообразовании сильно зависит от полярности растворителя. При уменьшении диэлектрической проницаемости среды (особенно ниже 4-5), например, путем прибавления неполярного растворителя, уменьшается чувствительность метода к содержанию комплексов.

Обращает на себя внимание тот факт, что увеличение электропроводности раствора всегда сопровождается изменением его окраски. И наоборот, в неполярных растворителях, например, диоксане, где не наблюдается повышения электропроводности, не увеличивается и оптическая плотность среды. Поэтому можно предположить, что эти явления имеют общую причину - образование диссоциированных на ионы комплексных соединений хлористого пренила с хлоридом металла. Поглощение света, по-видимому, связано со своеобразной структурой ненасыщенного карбониевого иона аллилового типа, который может переходить из одного состояния в другое (подвижное электронное облако) *:

$$
\left[\mathrm{R}-\mathrm{CH}=\mathrm{CH}-\mathrm{CH}_{2}+\right] \rightleftarrows\left[\mathrm{R}-\stackrel{+}{\mathrm{C}} \mathrm{H}-\mathrm{CH}=\mathrm{CH}_{2}\right] .
$$

Как видно из рис. 8, раствор хлористого пренила и электрофильных хлоридов металла в нитробензоле постепенно окрашивается. В течение первых 20 мин скорость увеличения оптической плотности больше, затем она падает. В случае $\mathrm{ZnCl}_{2}$ после максимума наблюдается уменьшение оптической плотности из-за того, что комплексное соединение плохо растворяется в нитробензоле. Обращает на себя внимание и тот факт, что разные хлориды металлов оказывают неодинаковое влияние на оптическую плотность раствора с избытком хлористого пре-

Рис. 8. Изменение оптической плотности $0,192 M$ раствора хлористого пренила в нитробензоле при $20^{\circ} \mathrm{C}$ после прибавления $0,0027 \mathrm{M}$ хлоридов металла (толщина слоя $20 \mathrm{m \mu}$ ): 1 $\mathrm{AlCl}_{3} ; 2-\mathrm{SnCl}_{4} ; 3-\mathrm{ZnCl}_{2} ; 4-\mathrm{TiCl}_{4}$; $5-\mathrm{SbCl}_{3}$.

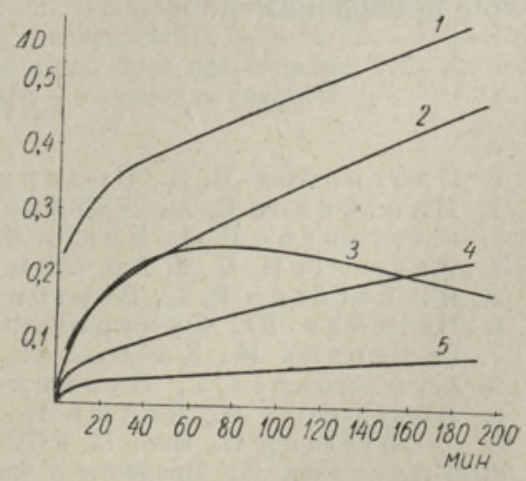

* Так называемая синиония, нли мезомерия, нонов такого типа описана в литеparype $\left[{ }^{15]}\right.$. 
нила. Несмотря на одинаковые концентрации реагирующих компонентов, скорости образования комплексных соединений изменяются в следующем порядке:

$$
\mathrm{AlCl}_{3}>\mathrm{ZnCl}_{2}>\mathrm{SnCl}_{4}>\mathrm{TiCl}_{4}>\mathrm{SbCl}_{3}
$$

На основании вышеизложенного можно сделать заключение, что скорость образования комплексных соединений хлористого пренила с хлоридами металла зависит от концентрации обоих компонентов, и реакция, по-видимому, носит характер бимолекулярного электрофильного замещения (атом хлора замещается комплексным анионом). Уравнения реакции первого порядка годны только при большом избытке одного компонента. Например, в случае теломеризации изопрена, когда имеется большой избыток гидрохлорида изопрена (смесь хлористого пренила и его изомера диметилвинилхлорметана, имеющих почти одинаковую скорость комплексообразования). Константы скорости реакции комплексообразования изменяются в широких пределах, так как от химического характера хлорида металла зависит энергия активации процесса, от характера растворителя - степень диссоциации комплексных соединений и энергия сольватации компонентов.

\section{Выводы}

1. Показана возможность исследования кинетики образования комплексов производных хлористого аллила с хлоридами металлов, имеющих координационно ненасыщенные валентности, методами определения удельной электропроводности, высокочастотной проводимости и оптической плотности среды.

2. Хлориды металлов располагаются по своей активности относительно ионизации $\mathrm{C}-\mathrm{Cl}$-связи при реакции их с производными хлористого аллила в ряд, отличающийся от соответствующего ряда катализаторов Фриделя-Крафтса-Густавсона.

3. Скорость реакции образования указанных комплексных соединений изменяется в широких пределах в зависимости от электрофильности хлорида металла, концентрации обоих компонентов, полярности растворителя и других факторов.

Автор выражает благодарность заведующему сектором органического синтеза Института химии АН ЭССР К. В. Лээтсу за ценные советы при проведении работы.

\section{ЛИ ТЕРАТ У РА}

1. Плотников В. А., Подорван И. М., ЖОХ, 3, 782 (1933).

2. Плотников В. А., Яку у сон С. И., ЖОХ, 5, 224 (1935); 6, 1960 (1936).

3. Плотников В. А., К и кец В. А., ЖРФХО. Часть хим., 62, вып, 5, 1001 (1930).

4. Pearse 11 H. C., J. Am. Chem. Soc., 73, 4681 (1951).

5. Richardson R. L., Benson S. W., J. Am. Chem. Soc., 73, 5096 (1951).

6. Невская Ю., Сумарокова Т., ЖОХ, 31, 345 (1961).

7. У с а нович М., К лимов В., С ум а роков а Т., ДАН СССР, 113, 364 (1957).

8. Сум арокова Т., Нурмакова А., ЖОХ, 30, 29 (1960).

9. Bodendorf K., Böhme H., Liebigs Ann. Chem., 516, 1 (1935); B öhme H., S i e r ing O., Ber., 71, 2372 (1938).

10. Глесстон С., Введение в электрохимию, Изд. иностр. лит., М., 1951.

11. Л э э т с K. В., ЖОХ, 28, 1823, 3096 (1958).

12. Петров А. А., Бальян Х. В., Херузе Ю. И., Швард Б. Ю., Черен ко в а Л. Л., ЖОХ, 28, 1435 (1958). 
13. Лээтс К. В., Пилявская А. И., Коровкина М. И., ЖОХ, 27, 2969 (1957).

14. Гу рьянова Е. Н., Гольдштейн И. П., ЖОХ, 32, 12 (1962).

15. Prevost C., Kirmann A., Bull. Soc. chim. France, 49, 194 (1931).

Институт химии

Академии наук Эстонской ССР
Поступила в редакцию

8/V 1964

E. $L I I V$

\section{KOMPLEKSOHENDITE MOODUSTUMISE KINEETIKAST PRENUULKLORIIDI JA ELEKTROFIILSETE METALLKLORIIDIDE VAHEL}

Isopreeni ioonkatalüütilise telomerisatsioonireaktsiooni kineetika ia mehhanismi väljaselgitamiseks tuleb kindlaks määrata vahepealsete aktiivsete kompleksühendite keemiline koostis ja moodustumise kiirus.

Käesolevas töös näidatakse, et katalüsaatorina kasutatavate metallkloriidide ja prenüülkloriidi vahelise reaktsiooni kineetikat on vōimalik uurida füüsikaliste meetoditega, määrates reaktsioonikeskkonna erielektrijuhtivuse, kõrgsageduse juhtivuse või optilise tiheduse tõusu. Nende meetodite abil määratakse kindlaks kompleksimoodustumisreaktsiooni hiirus, mis muutub suurtes piirides, olenevalt metallkloriidi elektrofiilsusest, mōlema reagendi kontsentratsioonist, lahustaja polaarsusest jt. faktoritest. Mainitud kompleksühendite moodustumist vōib vaadelda bimolekulaarse elektrofiilse asendusreaktsioonina. Elektrofiilsed metallkloriidid on väga erineva aktiivsusega ioniseerima $\mathrm{C}-\mathrm{Cl}$ seost allüülkloriidi derivaatides. Saadud aktiivsusrida ei lange kokku Friedeli-Kraftsi-Gustavsoni reaktsiooni katalüsaatorite vastava reaga.

\section{E. LIIV}

\section{KINETICS OF THE FORMATION OF COMPLEX COMPOUNDS OF 1-CHLORO-3-METHYL-2-BUTENE WITH ELECTROPHILIC METAL CHLORIDES}

For an elucidation of the kinetics and mechanism of the ion-catalytic telomerization reaction of isoprene, it proved of utmost necessity to define the chemical composition and rate of formation of intermediate active complex compounds. It is shown in the present work that for studying the kinetics of the reaction taking place between the metal chlorides (which are used as catalysts) and 1-chloro-3-methyl-2-butene, it is possible to use physical methods, and namely the electric conductivity, high-frequency conductivity, or the increase in optical density of the reaction-medium. With the help of these methods the rates of the reaction of the complex formation are defined, which fluctuate within considerable limits in dependence of the electrophilousness, concentration of both reagents, polarity of the solvent, and other factors. The above-mentioned reaction may be considered as a bimolecular electrophilic substitution reaction. The electrophilic metal chlorides possess very different degrees of activity in respect to their ability to ionize the $\mathrm{C}-\mathrm{Cl}$ bond in allyl-chloride derivates. The range of activity obtained does not coincide with the corresponding range of catalysts of the Fridel-Krafts-Gustavson reaction. 